\title{
Penilaian Kriteria Green Building Pada Pembangunan Gedung IsDB Project Berdasarkan Skala Indeks Menggunakan Greenship Versi 1.2 (Studi Kasus: Gedung Engineering Biotechnology Universitas Jember)
}

\author{
(Assessment Green Building Criteria for The Construction Of IsDB Project Building \\ By Index Scale Using Greenship Version 1.2 \\ (Case Study: Engineering Biotechnology Building University Of Jember))
}

Anik Ratnaningsih, Akhmad Hasanuddin, Richo Hermansa Jurusan Teknik Sipil, Fakultas Teknik, Universitas Jember (UNEJ)

Jln. Kalimantan 37, Jember 68121

E-mail: ratnaningsihanik@gmail.com

\begin{abstract}
Abstrak
Perencanaan dalam pembangunan saat ini harus mengacu dalam konsep Green Building yang merupakan salah satu wujud kepedulian terhadap kelestarian lingkungan di bidang konstruksi dalam menyikapi pemanasan global (global warming), untuk mengurangi efek dari global warming setiap perencanaan harus menerapkan konsep bangunan yang sesuai dengan iklim dan lingkungan alam sekitar. Perencanaan dengan konsep Green Building merupakan rangka dalam mencapai sertifikasi bangunan ramah lingkungan yang dikeluarkan oleh Green Building Council Indonesia (GBCI). Artikel ini bertujuan untuk mendapatkan index penilaian penerapan konsep Green Building pada gedung Engineering Biotechnology Universitas Jember. Metode penelitian pada artikel ini menggunakan skala indek perangkat penilaian Greenship Untuk Bangunan Baru versi 1.2, proses pengumpulan data dilakukan dengan cara observasi dan wawancara serta data sekunder dari pihak perencana meliputi gambar rencana, BoQ (Bill of Quantity) dan RKS (Rencana Kerja Syarat-syarat), tahap Recognisi Desain (DR) merupakan tahap penilaian yang dilakukan saat proyek dalam finalisasi desain dan perencanaan. Hasil penilaian dengan skala indek menunjukkan bahwa gedung mendapatkan total indek 30 poin, presentase sebesar 38,96\% dengan predikat Bronze/perunggu, apabila gedung menerapkan kriteria yang telah direkomedasikan seperti melengkapi data Amdal, RTH > 35\%, akses disabilitas, energy terbarukan, pengelolaan sampah, konservasi air, maka gedung dapat memperoleh nilai indek 46 poin dengan presentase $59.74 \%$ predikat Gold/emas.
\end{abstract}

Kata Kunci: GBCI, Green Building, IsDB, skala indek.

\begin{abstract}
Planning in the building to develop must be refer to the Green Building concept, which is a manifestation of concern for environmental sustainability in the field of construction to response the global warming, to reduce the effects of global warming. Every planning must be applied building concepts that are suitable to the climate and natural environment around. Planning with the Green Building concept is a framework for achieving environmentally friendly building certification issued by the Green Building Council Indonesia (GBCI). This article aims to obtain an index of assessment of the application of the concept of Green Building in the Engineering Biotechnology building at Jember University The research method in this article uses index scale the Greenship For New Building version 1.2, the process of collecting data is done by observation and interview as well as secondary data from the planner including the detail engineering design (DED), BoQ (Bill of Quantity) and technical specifications, the Design Recognition (DR) stage of assessment is carried out when the project is in the design and planning finalished. The results of the index scale assessment show that the building gets a total index of 30 points, a percentage of $38.96 \%$ with the predicate Bronze, if the building applies the recommended criteria such as completing Environmental Impact Assesment data, land scape $>35 \%$, disability access.
\end{abstract}

Keywords: GBCI, Green Building, IsDB,index scale.

\section{PENDAHULUAN}

Hal yang mendasari akan pentingnya Green Building saat ini adalah Global Warming Issue. Meningkatnya pembangunan yang diikuti dengan perkembangan perekonomian mengakibatkan kebutuhan energi nasional juga semakin meningkat (Putri, 2014). Energi listik di Indonesia sebagian besar didapatkan dari Pembangkit Listrik Tenaga Uap (PLTU) (BPPT, 2013). Hal ini merupakan suatu bukti yang menandakan besarnya penggunaan energi bahan bakar fosil yang dapat mengakibatkan menipisnya lapisan ozon dan berdampak pada pemanasan global (Global Warming). Intergovernmental Panel On Climate Change (IPCC) menyimpulkan terjadi peningkatan suhu di sebagian besar bumi sekitar $0,15-0,30{ }^{\circ} \mathrm{C}$ yang terjadi pada tahun 1990 2005 (Triana, 2008). Konsep Green Building hadir dan menjadi kebutuhan ditengah fenomena Global Warming, konsep tersebut dianggap sebagai salah satu solusi untuk mengurangi kerusakan lingkungan dan meminimalkan emesi karbon dari sektor konstruksi (Greenship, 2010 dalam Sobirin, 2014). Secara umum, Green Building merupakan suatu bangunan yang memenuhi persyaratan bangunan gedung dan memiliki kinerja terukur secara 
signifikan dalam penghematan energi, air, dan sumber daya lainnya yang efisien sejak perencanaan, pelaksanaan, konstruksi, pemanfaatan, pemeliharaan, sampai demonstruksi sehingga tidak berdampak negatif pada lingkungan (Nasir, 2015). Di Indonesia standard acuan untuk penilaian kriteria Green Building yaitu Greenship yang dikembangkan oleh Green Building Council Indonesia (GBCI), terdapat 6 (enam) aspek dalam penerapan Green Building berdasarkan perangkat Greenship untuk Bangunan Baru versi 1.2 meliputi Tepat Guna Lahan, Efisiensi dan Konservasi Energi, Konservasi Air, Sumber dan Siklus Material, Kualitas Udara Kenyamanan dan Manajemen Lingkungan Bangunan (GBCI, 2018). Masing-masing aspek terdiri atas nilai/poin yang memuat standar-standar baku dan rekomendasi untuk pencapaian standar tersebut (Kandita, 2017). Jika gedung dapat menerapkan kriteria yang telah direkomendasikan, maka gedung akan mengalami peningkatan pada predikat/rating, sehingga gedung dapat dikategorikan sebagai bangunan ramah lingkungan. Menurut Sari \& Putranto (2018), pada penelitian konsep bangunan hijau perolehan nilai dominan yaitu pada kategori Konservasi Air (WAC). Peningkatan poin nilai dapat dilakukan dengan memberikan rekomendasi dari segi arsitektural dan non arsitektural sehingga mampu menaikkan poin penilaian hingga predikat tertinggi yaitu platinum. Tujuan dari penulisan artikel ini untuk menilai penerapan dan menentukan predikat/rating Green Building pada Gedung IsDB Engineering Biotechnology Universitas Jember dengan menggunakan skala indek dalam tahap perencanaan/ tahap Recognisi Desain (DR), dengan harapan pada tahap pelaksanaan penerapan green building dapat dilakukan.

\section{Lokasi Penelitian}

\section{METODE PENELITIAN}

Penelitian ini dilakukan pada Gedung IsDBProject Engineering Biotechnology. Gedung tersebut berada di Universitas Jember, Jln. Kalimantan No.37 Kabupaten Jember, tepatnya diarea Fakultas Teknik

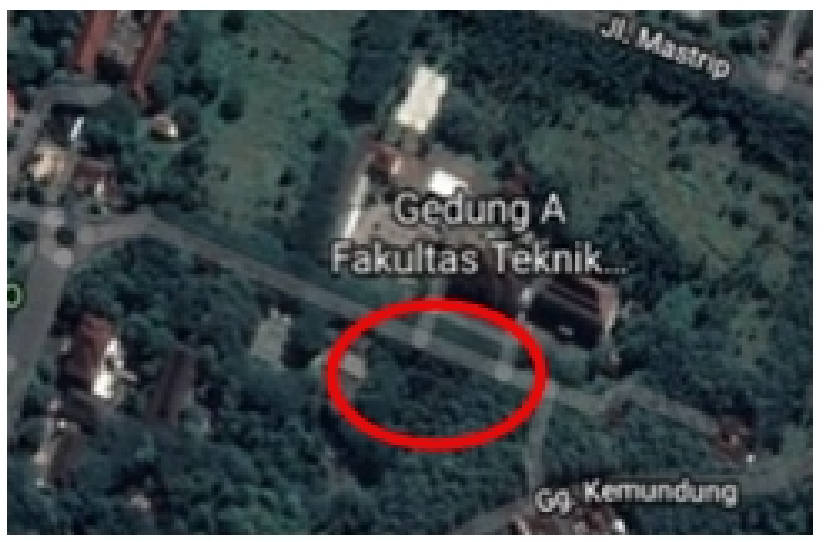

Gambar 1. Lokasi Penelitian Gedung IsDB Engineering Biotechnology

\section{Analisis Penilaian Greenship}

Konsep analisis data penelitian berfokus pada 6 aspek kriteria Greenship meliputi Tepat guna lahan, Efisiensi dan Konservasi Energi, Konservasi Air, Sumber Siklus
Material, Kesehatan Kenyamanan Ruang, dan Manajemen Lingkungan Bangunan. Masing-masing kriteria mengandung nilai dengan muatan poin tertentu yang didapatkan dengan beberapa perhitungan dan akan diolah untuk menentukan penilaian bangunan Green Building. Perhitungan yang digunakan pada setiap kategori Greenship dapat dilihat pada Tabel 1.

Tabel 1. Perhitungan Kategori Greenship

\begin{tabular}{|c|c|c|}
\hline Kat. & & Perhitungan \\
\hline \multirow[t]{7}{*}{ ASD } & & Lansekap \\
\hline & (a) & $\overline{\text { LuasTotalLahan }} \times 100$ \\
\hline & & $\sum(A n x \ln )$ \\
\hline & (b) & $\ln$ \\
\hline & (c) & $\operatorname{cxl} x a$ \\
\hline & (d) & Volumepenanganan \\
\hline & (i) & $\overline{\text { BebanVolumeLimpasan }} \times 100$ \\
\hline \multirow[t]{5}{*}{ EEC } & (a) & $($ OTTVuxAu $)+($ OTTVsxAs $)+($ OTTVbxAb $)+($ OTTVtx At $)$ \\
\hline & & $A u+A s+A b+A t$ \\
\hline & (b) & JumlahTitikLampuxDayaLampu \\
\hline & (D) & LuasRuang \\
\hline & (c) & $\frac{\text { OutputcoolingenergyinBTU }}{\text { Inputelectricalenergyin } W h}=E E R x \quad 0,293$ \\
\hline \multirow[t]{2}{*}{ WAC } & (a) & jumlahfiturairhemat \\
\hline & (a) & $\overline{\text { jumlahfiturairgedung }}$ \\
\hline \multirow[t]{2}{*}{$\mathrm{IHC}$} & (a) & $V b z=R p \cdot P z+R a \cdot A z$ \\
\hline & & $\frac{\text { areadenganoutsideview }}{\text { luas }} \times 100$ \\
\hline
\end{tabular}

Sumber: Divisi Rating dan Teknologi, 2013

Untuk menentukan poin aktual dan presentase penilaian dapat dilihat pada persamaan:

$\sum$ Poin $_{\text {aktual }}=\mathrm{ASD}+\mathrm{EEC}+\mathrm{WAC}+\mathrm{MRC}+\mathrm{IHC}+\mathrm{BEM}$

Presentase penilaian $=\frac{\sum \text { Poinaktual }}{\sum \text { Poinmaksimum }} \times 100 \%$

\section{Metode Penelitian}

Penelitian ini dilakukan dengan menggunakan metode kuantitatif pada kriteria Green Building berdasarkan perangkat penilaian Greenship untuk Bangunan Baru Versi 1.2 yang bertujuan untuk menilai konsep penerapan Green Building dan mengetahui predikat/rating pada gedung IsDB Engineering Biotechnology Universitas Jember. Pengumpulan data primer dilakukan dengan cara observasi dan wawancara kepada pihak terkait, selanjutnya melakukan pengumpulan data sekunder yang didapatkan dari pihak perencana yang meliputi gambar rencana, BoQ (Bill of Quantity), RKS (Rencana Kerja Syarat-syarat) serta dari studi literatur dan peraturan terkait, proses penilaian dilakukan pada beberapa kriteria dari setiap kategori yaitu uji kelayakan, kriteria prasyarat, kriteria kredit dan kriteria bonus, tahap yang digunakan dalam penilaian ini yaitu tahap Recognisi Design (DR) dengan nilai maksimum 77 poin, ada 4 (empat) penentuan dan penilaian tingkat predikat Greenship yaitu Platinum, Gold, Silver dan 
Bronze.Tahapan terakhir dari penelitian ini adalah melakukan evaluasi dan memberikan rekomendasi teknis, pemberian rekomendasi disesuaikan dengan kemampuan gedung untuk menerapkan tolok ukur dari setiap kategori, sehingga dapat membantu meningkatkan kualitas dan predikat Green Building pada tahap penilaian selanjutnya. Tahapan penelitian dapat dilihat pada Gambar 2.

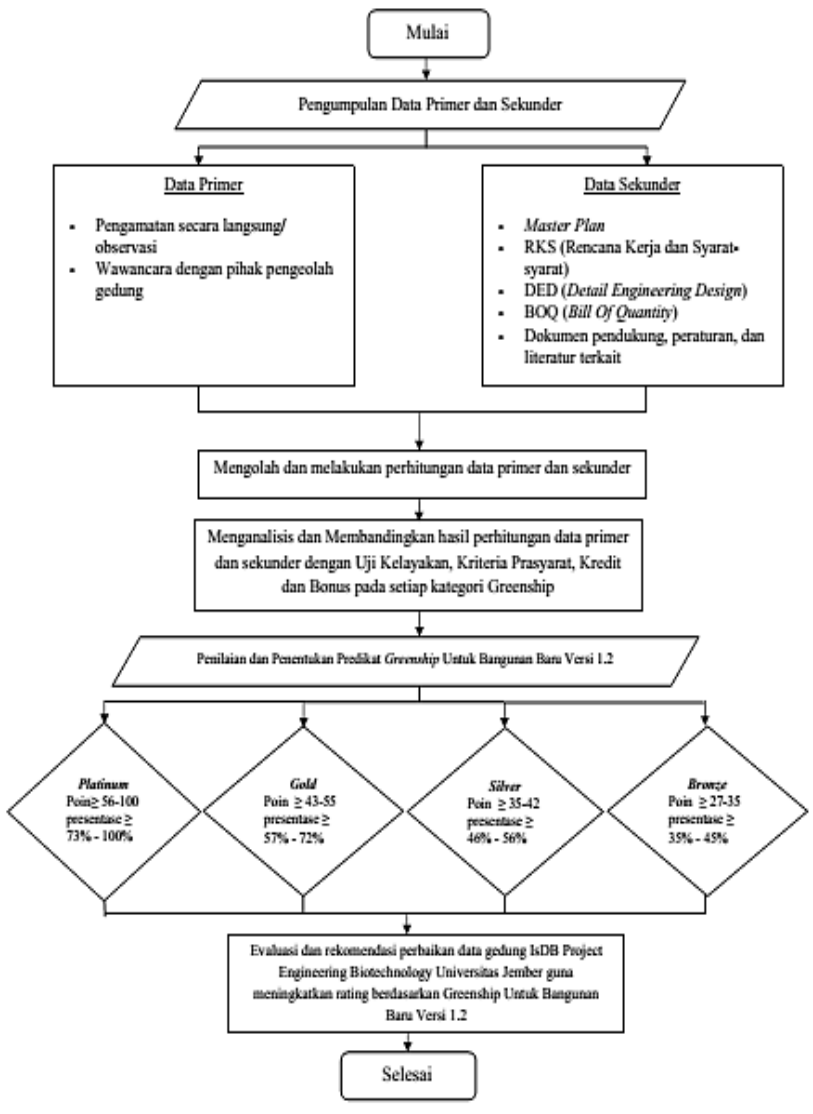

Gambar 2. Tahapan Penelitian.

\section{HASIL DAN PEMBAHASAN}

Hasil dan pembahasan pada poin ini mencakup hasil analisis Uji Kelayakan Bangunan (Eligibility), Kriteria prasyarat, kriteria kredit dan kriteria bonus menggunakan metode indek.

\section{Syarat Kelayakan Bangunan (Eligibility)}

1. Minimum Luas Gedung adalah $2500 \mathrm{~m}^{2}$

Tabel 2. Luasan lantai gedung IsDB Engineering Biotechnology

\begin{tabular}{lc}
\hline & Luas Per Lantai \\
\hline ATAP & $85 \mathrm{~m}^{2}$ \\
Lantai 6 & $728 \mathrm{~m}^{2}$ \\
Lantai 5 & $728 \mathrm{~m}^{2}$ \\
Lantai 4 & $728 \mathrm{~m}^{2}$ \\
Lantai 3 & $728 \mathrm{~m}^{2}$ \\
Lantai 2 & $848 \mathrm{~m}^{2}$ \\
Lantai 1 & $1.043 \mathrm{~m}^{2}$ \\
\hline TOTAL & $4.888 \mathbf{m}^{2}$ \\
\hline
\end{tabular}

Tabel 2 diatas menjelaskan penilaian luas lantai gedung telah terpenuhi dikarenakan luas gedung sebesar $4.888 \mathrm{~m}^{2}$ yang telah melebihi minimal luas gedung pada uji kelayakan sebesar $2500 \mathrm{~m}^{2}$

2. Ketersediaan Data Gedung Untuk Diakses GBC Indonesia Terkait Sertifikasi

Gedung IsDB Engineering Biotechnology belum memenuhi dalam kriteria ini dikarenakan penilaian gedung hanya dilakukan sebatas penelitian tidak untuk dilakukan sertifikasi Green Building secara resmi

3. Fungsi Gedung Sesuai Dengan Peruntukan Lahan RTRW Setempat

Berdasarkan Peraturan Daerah Kabupaten Jember Nomor 1 tahun 2015 Tentang Rencana Tata Ruang Wilayah (RTRW) Kabupaten Jember tahun 2015- 2035, lahan peruntukan yang ada dilokasi tapak area gedung IsDB Engineering Biotechnology telah memenuhi syarat tata ruang untuk fasilitas pendidikan.

4. Kepemilikan AMDAL Dan UKL/UPL

Hasil wawancara kepada pihak pengelola gedung IsDB Engineering Biotechnology, bahwa belum terdapat AMDAL pada gedung tersebut dikarenakan masih dalam proses, maka pada kriteria syarat kelayakan kepemilikan AMDAL belum terpenuhi.

5. Kesesuaian Gedung Terhadap Standart Keselamatan Kebakaran

Kemampuan bangunan gedung IsDB Engineering Biotechnology dalam menerapkan standart kebakaran telah memenuhi pengamanan terhadap bahaya kebakaran melalui sistem proteksi aktif yaitu Sistem Springkler, Hydrant dan APAR.

6. Kesesuaian Gedung Terhadap Standart Keselamatan Ketahanan Gempa

Berdasarkan hasil wawancara, gedung IsDB Engineering Biotechnology dirancang tahan terhadap bahaya gempa, dikarenakan pondasi yang digunakan pada gedung tersebut yaitu pondasi jenis bore pile salah satu jenis elemen pondasi dalam yang digunakan untuk bangunan tahan gempa sehingga pada kriteria kelayakan ini telah terpenuhi.

7. Kesesuaian Gedung Terhadap Standart Aksebilitas Difabel

Prinsip penerapan terhadap standart aksebilitas difabel gedung IsDB Engineering Biotechnology dilakukan dengan membandingkan fasilitas difabel pada data gambar perencanaan dengan Peraturan Menteri Pekerjaan Umum Nomor: 30/PRT/M/2006 tentang Pedoman Teknis Fasilitas dan Aksebilitas pada Bangunan Gedung dan Lingkungan. Penerapan aksesibilitas difabel tidak sepenuhnya diterapkan pada gedung. Sehingga pada kriteria kelayakan ini belum terpenuhi

Setelah melakukan Analisis Kelayakan Bangunan (eligibility), maka diperoleh hasil uji kelayakan seperti pada Tabel 3. 
Tabel 3. Matriks Kelayakan Bangunan (Eligibility)

\begin{tabular}{|c|c|c|}
\hline \multirow{2}{*}{ Kriteria } & \multicolumn{2}{|c|}{ Kelayakan } \\
\hline & $\mathbf{Y a}$ & Tidak \\
\hline
\end{tabular}

Ketersediaan data gedung untuk diakses

GBC Indonesia terkait sertifikasi

Fungsi gedung sesuai dengan peruntukan

lahan RT RW setempat

Kepemilikan AMDAL dan UKL/UPL

Kesesuaian gedung terhadap standart

keselamatan kebakaran

Kesesuaian gedung terhadap standart

keselamatan ketahanan gempa

Kesesuaian gedung terhadap standart $\sqrt{ }$

aksebilitas difabel

Menjelaskan pada Tabel 3, Uji Kelayakan Bangunan (Eligibility) terdapat 4 (empat) kriteria telah memenuhi standart uji kelayakan, sedangkan 3 (tiga) kriteria belum memenuhi.

\section{Tepat Guna Lahan (ASD)}

Perolehan indek hasil analisis setiap kriteria dalam kategori Tepat Guna Lahan (ASD) dapat dilihat pada Tabel 4.

Tabel 4. Ringkasan Perolehan Poin Kategori Tepat Guna Lahan (ASD)

\begin{tabular}{|c|c|c|c|c|c|}
\hline \multirow{2}{*}{ Kode } & \multirow{2}{*}{ Kriteria } & \multirow{2}{*}{$\begin{array}{l}\text { Tolok } \\
\text { Ukur }\end{array}$} & \multicolumn{2}{|c|}{ Memenuhi } & \multirow{2}{*}{ indek } \\
\hline & & & $\mathbf{Y a}$ & Tidak & \\
\hline ASD P & $\begin{array}{l}\text { Area Dasar } \\
\text { Hijau }\end{array}$ & $\mathrm{P}$ & $\sqrt{ }$ & & \\
\hline \multirow[t]{2}{*}{ ASD 1} & Pemilihan & 1 & $\sqrt{ }$ & & 1 \\
\hline & Tapak & 2 & & $\sqrt{ }$ & 0 \\
\hline \multirow[t]{4}{*}{ ASD 2} & Aksebilitas & 1 & $\sqrt{1}$ & & 1 \\
\hline & Komunitas & 2 & $\sqrt{ }$ & & 1 \\
\hline & & 3 & $\sqrt{ }$ & & 2 \\
\hline & & 4 & & $\sqrt{ }$ & 0 \\
\hline \multirow[t]{2}{*}{ ASD 3} & Transportasi & 1 & & $\sqrt{ }$ & 0 \\
\hline & Umum & 2 & & $\sqrt{ }$ & 0 \\
\hline \multirow[t]{3}{*}{ ASD 4} & Fasilitas & 1 & & $\sqrt{ }$ & 0 \\
\hline & Pengguna & 2 & & $\sqrt{ }$ & 0 \\
\hline & Sepeda & & & & \\
\hline \multirow[t]{3}{*}{ ASD 5} & Lansekap Pada & $1 \mathrm{~A}$ & & $\sqrt{ }$ & 0 \\
\hline & Lahan & 1B & & $\sqrt{ }$ & 0 \\
\hline & & 2 & & $\sqrt{ }$ & 0 \\
\hline \multirow[t]{3}{*}{ ASD 6} & Iklim Mikro & $1 \mathrm{~A} / 1 \mathrm{~B}$ & $\sqrt{1}$ & & 1 \\
\hline & & 2 & $\sqrt{ }$ & & 1 \\
\hline & & $3 \mathrm{~A} / 3 \mathrm{~B}$ & $\sqrt{ }$ & & 1 \\
\hline \multirow[t]{3}{*}{ ASD 7} & Manajemen & $1 \mathrm{~A} / 1 \mathrm{~B}$ & & $\sqrt{ }$ & 0 \\
\hline & Limpasan Air & 2 & $\sqrt{ }$ & & 1 \\
\hline & Hujan & 3 & & $\sqrt{ }$ & 0 \\
\hline
\end{tabular}

\section{Total Indek}

Menjelaskan kategori Tepat Guna Lahan (ASD) pada kriteria prasyarat telah memenuhi area dasar hijau, sedangkan pada kriteria kredit mendapatkan perolehan nilai indek 9 (sembilan). Kategori tepat guna lahan merupakan usaha perencanaan pembangunan yang memperhatikan sarana dan prasarana dalam bentuk efisiensi energi dan biaya.

\section{Efisiensi dan Konservasi Energi (EEC)}

Perolehan poin hasil analisis setiap kriteria kredit dan bonus dalam kategori Efisiensi dan Konservasi Energi (EEC) disajikan dalam Tabel 5.

Tabel 5. Ringkasan Perolehan Poin Efisiensi dan onservasi Energi (EEC)

\begin{tabular}{|c|c|c|c|c|c|}
\hline \multirow{2}{*}{ Kode } & \multirow{2}{*}{ Kriteria } & \multirow{2}{*}{$\begin{array}{l}\text { Tolok } \\
\text { Ukur }\end{array}$} & \multicolumn{2}{|c|}{ Memenuhi } & \multirow{2}{*}{ indek } \\
\hline & & & Ya & Tidak & \\
\hline$\overline{\text { EEC P1 }}$ & $\begin{array}{l}\text { Pemasangan } \\
\text { Sub-Meter }\end{array}$ & $P$ & & $\sqrt{ }$ & \\
\hline$\overline{\text { EEC P2 }}$ & $\begin{array}{l}\text { Perhitungan } \\
\text { OTTV }\end{array}$ & $\mathrm{P}$ & & $\sqrt{ }$ & \\
\hline \multirow[t]{2}{*}{ EEC 1} & \multicolumn{5}{|c|}{ Efisiensi dan Konservasi Energi (IC) } \\
\hline & OTTV & $\begin{array}{l}1 \\
2 \\
\end{array}$ & $\begin{array}{l}\sqrt{ } \\
\sqrt{ }\end{array}$ & & $\begin{array}{l}3 \\
1 \\
\end{array}$ \\
\hline \multirow{8}{*}{ Kode } & \multirow{2}{*}{ Kriteria } & \multirow{2}{*}{$\begin{array}{l}\text { Tolok } \\
\text { Ukur }\end{array}$} & \multicolumn{2}{|c|}{ Memenuhi } & indek \\
\hline & & & Ya & Tidak & Indek \\
\hline & Pencahayaan & 1 & $\sqrt{ }$ & & 1 \\
\hline & Buatan & 2 & $\sqrt{ }$ & & 1 \\
\hline & & 3 & & $\sqrt{ }$ & 0 \\
\hline & & 4 & $\sqrt{ }$ & & 1 \\
\hline & $\begin{array}{l}\text { Transportasi } \\
\text { Vertikal }\end{array}$ & 1 & $\sqrt{ }$ & & 1 \\
\hline & $\begin{array}{l}\text { Sistem } \\
\text { Pengkondisian } \\
\text { Udara }\end{array}$ & 1 & $\sqrt{ }$ & & 2 \\
\hline EEC 3 & Ventilasi & 1 & $\sqrt{ }$ & & 1 \\
\hline EEC 4 & $\begin{array}{l}\text { Pengaruh } \\
\text { Perubahan } \\
\text { Iklim } \\
\end{array}$ & 1 & & $\sqrt{ }$ & 0 \\
\hline EEC 5 & $\begin{array}{l}\text { Energi } \\
\text { Terbarukan } \\
\text { dalam Tapak }\end{array}$ & 1 & & $\sqrt{ }$ & 0 \\
\hline
\end{tabular}

Menjelaskan bahwa dalam kategori Efisiensi dan Konservasi Energi (EEC) pada kriteria prasyarat belum memenuhi, sedangkan pada kriteria kredit mendapatkan perolehan nilai indek 11 (sebelas). Penilaian kategori efisiensi dan konservasi energi merupakan konsep sosialisasi yang dapat mendukung prosedur penghematan listrik.

Konservasi Air (WAC)

Perolehan poin hasil analisis setiap kriteria kredit dalam kategori Konservasi Air (WAC) disajikan dalam Tabel 6. 
Tabel 6. Ringkasan Perolehan Poin Konservasi Air (WAC)

\begin{tabular}{|c|c|c|c|c|c|}
\hline \multirow{2}{*}{ Kode } & \multirow{2}{*}{ Kriteria } & \multirow{2}{*}{$\begin{array}{l}\text { Tolok } \\
\text { Ukur }\end{array}$} & \multicolumn{2}{|c|}{ Memenuhi } & \multirow{2}{*}{ indek } \\
\hline & & & $\mathbf{Y a}$ & Tidak & \\
\hline WAC P1 & Meteran Air & $\mathrm{P}$ & & $\sqrt{ }$ & \\
\hline \multirow[t]{3}{*}{ WAC P2 } & Perhitungan & $\mathrm{P}$ & & $\sqrt{ }$ & \\
\hline & Penggunaan & & & & \\
\hline & Air & & & & \\
\hline \multirow[t]{2}{*}{ WAC 1} & Pengurangan & 1 & & $\sqrt{ }$ & 0 \\
\hline & Pengunaan Air & 2 & & $\sqrt{ }$ & 0 \\
\hline WAC 2 & Fitur Air & $\begin{array}{c}1 \mathrm{~A} / 1 \mathrm{~B} / \\
1 \mathrm{C}\end{array}$ & $\sqrt{ }$ & & 3 \\
\hline WAC 3 & Daur Ulang Air & $1 \mathrm{~A} / 1 \mathrm{~B}$ & & $\sqrt{ }$ & 0 \\
\hline \multirow[t]{2}{*}{ WAC 4} & Sumber Air & $1 \mathrm{~A} /$ & & $\sqrt{ }$ & 0 \\
\hline & Alternatif & $1 \mathrm{~B} / 1 \mathrm{C}$ & & & \\
\hline \multirow[t]{2}{*}{ WAC 5} & Penampungan & $1 \mathrm{~A} / 1 \mathrm{~B} / 1$ & & $\sqrt{ }$ & 0 \\
\hline & Air Hujan & $\mathrm{C}$ & & & \\
\hline \multirow[t]{2}{*}{ WAC 6} & Efisiensi & 1 & & $\sqrt{ }$ & 0 \\
\hline & Pengairan Air & 2 & & $\sqrt{ }$ & 0 \\
\hline
\end{tabular}

Kategori Konservasi Air (WAC) pada kriteria prasyarat belum memenuhi, sedangkan pada kriteria kredit mendapatkan perolehan nilai indek sebesar 3 (tiga), dalam kategori konservasi air dilakukan penilaian upaya serta langkah penghematan air pada gedung.

Sumber Siklus Material (MRC)

Perolehan poin hasil analisis setiap kriteria kredit dalam kategori Sumber Siklus Material (MRC) disajikan dalam Tabel 7.

Tabel 7. Ringkasan Perolehan Poin Sumber Siklus Material (MRC)

\begin{tabular}{|c|c|c|c|c|c|}
\hline \multirow[t]{2}{*}{ Kode } & \multirow{2}{*}{ Kriteria } & \multirow{2}{*}{$\begin{array}{l}\text { Tolok } \\
\text { Ukur } \\
\end{array}$} & \multicolumn{2}{|c|}{ Memenuhi } & \multirow{2}{*}{ indek } \\
\hline & & & Ya & Tidak & \\
\hline MRC P & $\begin{array}{l}\text { Refrigeran } \\
\text { Fundamental }\end{array}$ & $\mathrm{P}$ & & $\sqrt{ }$ & \\
\hline MRC 1 & $\begin{array}{l}\text { Penggunaan } \\
\text { gedung dan } \\
\text { material bekas }\end{array}$ & $\begin{array}{l}1 \mathrm{~A} \\
1 \mathrm{~B}\end{array}$ & & $\begin{array}{l}\sqrt{ } \\
\sqrt{ }\end{array}$ & $\begin{array}{l}0 \\
0\end{array}$ \\
\hline MRC 2 & $\begin{array}{l}\text { Material } \\
\text { melalui proses } \\
\text { ramah } \\
\text { lingkungan }\end{array}$ & $\begin{array}{l}1 \\
2 \\
3\end{array}$ & & $\begin{array}{l}\sqrt{ } \\
\sqrt{ } \\
\sqrt{ }\end{array}$ & $\begin{array}{l}0 \\
0 \\
0\end{array}$ \\
\hline MRC 3 & $\begin{array}{l}\text { Penggunaan } \\
\text { Bahan yang } \\
\text { tidak } \\
\text { mengandung } \\
\text { BPO }\end{array}$ & 1 & $\sqrt{ }$ & & 2 \\
\hline MRC 4 & $\begin{array}{l}\text { Kayu } \\
\text { Bersertifikat }\end{array}$ & $\begin{array}{l}1 \\
2\end{array}$ & & $\begin{array}{l}\sqrt{ } \\
\sqrt{ }\end{array}$ & $\begin{array}{l}0 \\
0\end{array}$ \\
\hline MRC 5 & $\begin{array}{l}\text { Material Pra } \\
\text { Fabrikasi }\end{array}$ & 1 & & $\sqrt{ }$ & 0 \\
\hline MRC 6 & Material Lokal & $\begin{array}{l}1 \\
2\end{array}$ & & $\begin{array}{l}\sqrt{ } \\
\sqrt{ }\end{array}$ & $\begin{array}{l}0 \\
0\end{array}$ \\
\hline & & & Tot & Indek & 2 \\
\hline
\end{tabular}

Kategori Sumber dan Siklus Material (MRC) pada kriteria prasyarat belum memenuhi, sedangkan pada kriteria kredit mendapatkan perolehan nilai sebesar 2 (dua) poin. Kategori sumber dan siklus material diterapkan dimana sebagai bentuk usaha untuk mendukung perkembangan industri material bangunan yang ramah lingkungan.

\section{Kualitas Udara Dan Kenyamanan (IHC)}

Perolehan poin hasil analisis setiap kriteria kredit dalam kategori Kualitas Udara Dan Kenyamanan (IHC) disajikan dalam Tabel 8.

Tabel 8. Ringkasan Perolehan Poin Kualitas Udara Dan Kenyamanan (IHC)

\begin{tabular}{|c|c|c|c|c|c|}
\hline \multirow[t]{2}{*}{ Kode } & \multirow{2}{*}{ Kriteria } & \multirow{2}{*}{$\begin{array}{l}\text { Tolok } \\
\text { Ukur }\end{array}$} & \multicolumn{2}{|c|}{ Memenuhi } & \multirow{2}{*}{ indek } \\
\hline & & & $\mathbf{Y a}$ & Tidak & \\
\hline$\overline{\mathrm{IHC}} \mathrm{P}$ & $\begin{array}{l}\text { Introduksi Udara } \\
\text { Luar }\end{array}$ & $\mathrm{P}$ & & $\sqrt{ }$ & \\
\hline$\overline{\mathrm{IHC}} 1$ & $\begin{array}{l}\text { Pemantauan } \\
\text { Kadar CO2 }\end{array}$ & 1 & & $\sqrt{ }$ & 0 \\
\hline$\overline{\mathrm{IHC}} 2$ & $\begin{array}{l}\text { Kendali Asap } \\
\text { Rokok }\end{array}$ & 1 & $\sqrt{ }$ & & 2 \\
\hline IHC 3 & Polutan Kimia & $\begin{array}{l}1 \\
2 \\
3\end{array}$ & $\begin{array}{l}\sqrt{ } \\
\sqrt{ }\end{array}$ & $\sqrt{ }$ & $\begin{array}{l}1 \\
0 \\
1\end{array}$ \\
\hline $\mathrm{IHC} 4$ & $\begin{array}{l}\text { Pemandangan } \\
\text { Keluar Gedung }\end{array}$ & 1 & $\sqrt{ }$ & & 1 \\
\hline
\end{tabular}

\begin{tabular}{|c|c|c|c|c|c|}
\hline \multirow[t]{2}{*}{ Kode } & \multirow{2}{*}{ Kriteria } & \multirow{2}{*}{$\begin{array}{l}\text { Tolok } \\
\text { Ukur }\end{array}$} & \multicolumn{2}{|c|}{ Memenuhi } & \multirow{2}{*}{ indek } \\
\hline & & & Ya & Tidak & \\
\hline IHC 5 & $\begin{array}{l}\text { Kenyamanan } \\
\text { Visual }\end{array}$ & 1 & & $\sqrt{ }$ & 0 \\
\hline IHC 6 & $\begin{array}{l}\text { Kenyamanan } \\
\text { Termal }\end{array}$ & 1 & & $\sqrt{ }$ & 0 \\
\hline IHC 7 & $\begin{array}{l}\text { Tingkat } \\
\text { Kebisingan }\end{array}$ & 1 & & $\sqrt{ }$ & 0 \\
\hline
\end{tabular}

Menjelaskan pada Kategori Kualitas Udara Dan Kenyamanan (IHC) pada kriteria prasyarat belum memenuhi, sedangkan pada kriteria kredit mendapatkan perolehan nilai indek sebesar 5 (lima). Usaha pengendalian kualitas udara yang mengacu pada praktik lingkungan dalam ruang yang sehat dan nyaman termasuk penilaian dalam kategori kualitas udara dan kenyamanan.

\section{Manajemen Lingkungan Bangunan (BEM)}

Perolehan poin hasil analisis setiap kriteria kredit dalam kategori Manajemen Lingkungan Bangunan (BEM) disajikan dalam Tabel 9. 
Tabel 9. Ringkasan Perolehan Poin Manajemen Lingkungan Bangunan (BEM)

\begin{tabular}{|c|c|c|c|c|c|}
\hline \multirow[t]{2}{*}{ Kode } & \multirow{2}{*}{ Kriteria } & \multirow{2}{*}{$\begin{array}{l}\text { Tolok } \\
\text { Ukur }\end{array}$} & \multicolumn{2}{|c|}{ Memenuhi } & \multirow{2}{*}{ indek } \\
\hline & & & Ya & Tidak & \\
\hline BEM P & $\begin{array}{l}\text { Dasar } \\
\text { Pengelolahan } \\
\text { Sampah }\end{array}$ & $\mathrm{P}$ & & $\sqrt{ }$ & \\
\hline$\overline{\text { BEM } 1}$ & $\begin{array}{l}\text { GP sebagai } \\
\text { Anggota Tim } \\
\text { Proyek }\end{array}$ & 1 & & $\sqrt{ }$ & 0 \\
\hline BEM 2 & $\begin{array}{l}\text { Polusi dari } \\
\text { Aktivitas } \\
\text { Konstruksi }\end{array}$ & 1 & & $\sqrt{ }$ & 0 \\
\hline BEM 3 & $\begin{array}{l}\text { Pengolahan } \\
\text { Sampah } \\
\text { Tingkat Lanjut }\end{array}$ & 1 & & $\sqrt{ }$ & 0 \\
\hline$\overline{\text { BEM } 4}$ & $\begin{array}{l}\text { Sistem } \\
\text { Komisioning } \\
\text { yang Baik dan } \\
\text { Benar }\end{array}$ & $\begin{array}{l}1 \\
2\end{array}$ & & $\begin{array}{l}\sqrt{ } \\
\sqrt{ }\end{array}$ & 0 \\
\hline BEM 5 & $\begin{array}{l}\text { Penyerahan } \\
\text { Data Green } \\
\text { Building }\end{array}$ & 1 & & $\sqrt{ }$ & 0 \\
\hline$\overline{\text { BEM } 6}$ & $\begin{array}{l}\text { Kesepakatan } \\
\text { Dalam } \\
\text { Melakukan } \\
\text { Aktivitas Fit } \\
\text { Out }\end{array}$ & 1 & & $\sqrt{ }$ & 0 \\
\hline BEM 7 & $\begin{array}{l}\text { Survei } \\
\text { Pengguna } \\
\text { Gedung } \\
\end{array}$ & 1 & & $\sqrt{ }$ & 0 \\
\hline Total In & dek & & & & 0 \\
\hline
\end{tabular}

Kategori Manajemen Lingkungan Bangunan (BEM) pada kriteria prasyarat belum memenuhi, sedangkan pada kriteria kredit mendapatkan perolehan nilai indek sebesar 0 (nol) atau tidak memperoleh poin. Penerapan manajemen lingkungan bangunan merupakan bentuk usaha untuk mengarahkan tindakan operasional bangunan agar menunjukkan hasil bangunan yang ramah lingkungan.

\section{Penentuan Tingkat Predikat Greenship}

Pada tahap ini dilakukan penilaian (Design RecognitionDR) dengan maksimum nilai indek 77 (tujuh puluh tujuh).. Tahap ini dilakukan selama gedung masih dalam tahap perencanaan.

Total index yang diperoleh dari masing-masing kategori kemudian dihitung menggunakan persamaan 11:

$\sum$ Index $_{\text {aktual }}=9+11+3+2+5+0$

$$
=30
$$

Untuk mengetahui persetase nilai indeks hasil penilaian, maka dihitung menggunakan persamaan 12:

$\begin{aligned} \text { Presentase Penilaian } & =\frac{30}{77} \times 100 \% \\ & =38.96 \%\end{aligned}$
Tabel 10. Total Nilai Hasil Penilaian Green Building Gedung Engineering Biotechnology

\begin{tabular}{|c|c|c|c|}
\hline \multirow[t]{2}{*}{ Kategori } & \multicolumn{3}{|c|}{ Jumlah Nilai } \\
\hline & Kredit & Bonus & Presentase \\
\hline Tepat Guna Lahan & 9 & - & $11.69 \%$ \\
\hline $\begin{array}{l}\text { Efisiensi dan } \\
\text { Konservasi Energi }\end{array}$ & 11 & 0 & $14.28 \%$ \\
\hline Konservasi Air & 3 & - & $3.90 \%$ \\
\hline $\begin{array}{l}\begin{array}{l}\text { Sumber } \\
\text { Material }\end{array} \\
\end{array}$ & 2 & - & $2.60 \%$ \\
\hline $\begin{array}{l}\text { Kualitas Udara \& } \\
\text { Kenyamanan Udara } \\
\text { dalam Ruang }\end{array}$ & 5 & - & $6.49 \%$ \\
\hline $\begin{array}{l}\text { Manajemen } \\
\text { Lingkungan } \\
\text { Bangunan } \\
\end{array}$ & 0 & - & $0 \%$ \\
\hline Total & 30 & $\mathbf{0}$ & $38.96 \%$ \\
\hline
\end{tabular}

Perbandingan poin maksimum Greenship dengan poin aktual disajikan dalam grafik pada Gambar 3.

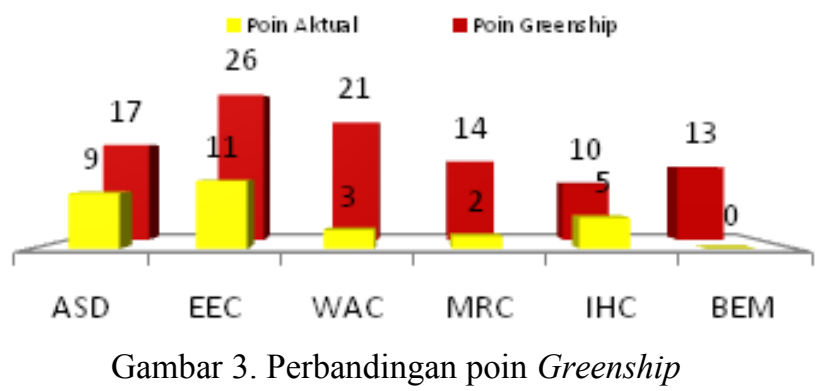

Hasil akhir penilaian didapatkan total indek sebesar $30(\mathrm{t}$ puluh) dengan presentase $38.96 \%$ yang dikategorikan sebagai gedung berpredikat Bronze (perunggu).

\section{Perolehan Total Poin dari Hasil Evaluasi dan Rekomendasi}

Pemberian rekomendasi teknis perbaikan Gedung Engineering Biotechnology disesuaikan dengan kemampuan gedung, sehingga mampu meningkatkan kualitas dan rating, rekomendasi teknis pembangunan gedung dapat dilihat pada Tabel 11.

Tabel 11. Rekomendasi Teknis

\begin{tabular}{|c|c|}
\hline Kategori & Rekomendasi \\
\hline \multicolumn{2}{|c|}{ Uji Kelayakan (Eligibility) } \\
\hline \multicolumn{2}{|c|}{ Dokumen Amdal Melengkapi } \\
\hline \multirow[t]{4}{*}{ dan UKL/UPL } & berdasarkan \\
\hline & Pemerintah Republik Indonesia Nomor 27 \\
\hline & Tahun 2012 tentang Izin Lingkungan pada \\
\hline & $\begin{array}{l}\text { BAB II tentang Penyusunan Amdal dan } \\
\text { UKL-UPL }\end{array}$ \\
\hline Standart & Meningkatkan penerapan terhadap standart \\
\hline Aksebilitas & aksesibilitas difabel dengan melakukan \\
\hline Difabel & $\begin{array}{l}\text { perbaikan atau melengkapi beberapa area } \\
\text { yang belum sesuai dengan pedoman teknis }\end{array}$ \\
\hline & Peraturan Menteri Pekerjaan Umum Nomor \\
\hline
\end{tabular}




\begin{tabular}{ll}
\hline Tepat Guna Lahan (ASD) \\
\hline $\begin{array}{l}\text { Transportasi } \\
\text { Umum }\end{array}$ & $\begin{array}{l}\text { Menamabah adanya shuttle bus yang } \\
\text { diterapkan dikawasan Universitas Jember } \\
\text { untuk pengguna gedung }\end{array}$ \\
Fasilitas & $\begin{array}{l}\text { Menyediakan tempat parkir untuk } \\
\text { Pengguna } \\
\text { pengguna sepeda sebanyak 1 unit parkir per }\end{array}$ \\
Sepeda & 20 pengguna gedung hingga maksimal 100 \\
Lansekap pada & Menit parkir sepeda. \\
Lahan & tajuk 5 m sebanyak 3 pohon atau \\
& menggunakan pohon diameter tajuk \\
& dibawah $5 \mathrm{~m}$ dan menambah pohon \\
\hline Manajemen & Membuat 2 (dua) tangki penampungan air \\
Limpasan & Airhujan dengan masing-masing berkapasitas \\
Hujan & $56 \mathrm{~m}^{3}$. Air hujan yang ditampung dapat \\
& digunakan untuk kebutuhan penyiraman \\
tanaman
\end{tabular}

Efisiensi dan Konservasi Energi (EEC)

Prasyarat Memasang Kwh meter dan emerencanakan

Pemasangan Sub penempatan semua sub-meteran agar

Meter mudah diakses .

Pencahayaan Menggunakan sensor gerak yang dikaitkan

Buatan dengan zonasi pencahayaan pada zona kerja pengguna ruangan.

Energi Diperlukan adanya penggunaan energi Terbarukan terbarukan dalam tapak seperti penggunaan Dalam Tapak teknologi photovoltaics (PV) langsung mengkonversi sinar matahari menjadi listrik tenaga surya

Konservasi Air (WAC)

Prasyarat Memasang alat meteran air (volume meter) Pemasangan Alatyang ditempatkan pada lokasi-lokasi Meteran Air tertentu pada sistem distribusi air

Daur Ulang Air Memanfaatkan air hasil daur ulang dari STP yang ada untuk kebutuhan flushing dan menyediakan tangki untuk penampungan air daur ulang.

Sumber Air Membuat sistem untuk pemurnian air Alternatif alternatif agar dapat digunakan sebagai air bersih

\begin{tabular}{ll}
\hline \multicolumn{1}{c}{ Kategori } & \multicolumn{1}{c}{ Rekomendasi } \\
\hline Penampungan & Jika tangki yang sudah direkomendasikan \\
Air Hujan & pada ASD 7 sudah diterapkan. Maka 50\% \\
& air hujan yang jatuh di atas atap sudah \\
& tertampung dalam tangki tersebut \\
Kfing
\end{tabular}

Kebutuhan irigasi untuk lansekap dapat Pengairan Air diambil dari tangki penampungan tersebut, sehingga tidak perlu memakai air dari sumber primer.

Manajemen Lingkungan Bangunan (BEM)

Prasyarat Menyediakan instalasi atau fasilitas untuk Manajemen memilah dan mengumpulkan sampah Dasar Sampah sejenis sampah rumah tangga (UU No.18 Tahun 2008) berdasarkan jenis organik dan anorganik serta perlu adanya perencanaan untuk Tempat Pembuangan Sampah (TPS) lingkungan Universitas Jember

Pengelolahan Mengolah limbah organik dan anorganik $\underline{\text { Sampah Tingkat gedung yang dilakukan secara mandiri }}$

\begin{tabular}{ll}
\hline Lanjut & $\begin{array}{l}\text { maupun bekerjasama dengan pihak ketiga } \\
\text { sehingga menambah nilai manfaat dan } \\
\text { dapat mengurangi dampak pada lingkungan }\end{array}$ \\
\hline
\end{tabular}

Kriteria yang telah direkomendasikan, maka gedung akan mendapatkan peningkatan poin dan rating, total hasil nilai evaluasi dan rekomendasi dapat dilihat pada Tabel 12.

Tabel 12. Total Hasil Nilai dari Evaluasi dan Rekomendasi

\begin{tabular}{|c|c|c|c|}
\hline \multirow[t]{2}{*}{ Kategori } & \multicolumn{3}{|c|}{ Jumlah Nilai } \\
\hline & Kredit & Bonus & Presentase \\
\hline Tepat Guna Lahan & 14 & - & $18.18 \%$ \\
\hline $\begin{array}{ll}\text { Efisiensi } & \text { dan } \\
\text { Konservasi Energi } & \end{array}$ & 12 & 5 & $15.58 \%$ \\
\hline Konservasi Air & 11 & - & $14.29 \%$ \\
\hline $\begin{array}{lll}\begin{array}{l}\text { Sumber } \\
\text { Material }\end{array} & \& & \text { Siklus } \\
\end{array}$ & 2 & - & $2.60 \%$ \\
\hline Kualitas & 5 & - & \\
\hline $\begin{array}{l}\text { Kenyamanan } \\
\text { dalam Ruang }\end{array}$ & & & $6.49 \%$ \\
\hline $\begin{array}{l}\text { Manajemen } \\
\text { Lingkungan Bangunan }\end{array}$ & 2 & - & $2.60 \%$ \\
\hline Total & 46 & 5 & $59.74 \%$ \\
\hline
\end{tabular}

\section{KESIMPULAN}

Hasil indek penilaian pada setiap kategori Greenship pada perencanaan gedung IsDB Engineering Biotechnology didapatkan nilai indek 30 (tiga puluh) dengan presentase 38.96\%, maka gedung IsDB Engineering Biotechnology dapat dikategorikan sebagai Green Building dengan peringkat Bronze/Perunggu. Peringkat bronze dapat ditingkatkan menjadi gold dengan indek 46 (empat puluh enam), presentase 59,74\% predikat Gold/Emas, dengan cara meningkatkan RTH, melengkapi dokumen AMDAL, pengelolaan energi konservasi air, dan pengelolaan limbah,

\section{Saran}

Bahwa untuk menilai kesempurnaan Green Building dapat dilakukan pada tahap perencanaan hingga tahap operasional dengan mempertimbangkan penilaian pencahayaan alami, pengaruh perubahan iklim dan kenyamanan termal, penilaian tersebut dapat dilakukan ketika gedung selesai, serta dapat dilakukan penilaian hingga tahap Final Asessment (FA) melihat kondisi pembangunan gedung yang hampir selesai.

\section{DAFTAR PUSTAKA}

[1] BPPT (Badan Pengkajian dan Penerapan Teknologi). (2013). "Daya Dukung Pembangkit Listrik Tenaga Uap Berbahan Bakar Batu Bara. Teknologi Konversi dan Konservasi Energi, Teknologi Informasi, Energi dan Material ISBN 978-979-3733-97-5.

[2] Divisi Rating Dan Teknologi. (2013). Perangkat Penilaian Greenship Untuk Bangunan Baru Versi 1.2. Green Building Council Indonesia.

[3] Green Building Council Indonesia. (2018). Rating Tools. Retrieved November 22, 2018, from http://gbcindonesia.org/.

[4] Kandita, Akmalah, E., \& Irawati, I. (2017). "Kajian Kategori Tepat Guna Lahan Dalam Penerapan Konsen 
Green Building Di Itenas”. Jurnal Teknik Sipil Institut Nasional Bandung, 22-27.

[5] Nasir, R. Y. (2015). Sekilas Tentang Green Building. Teknologi Bangunan Hijau Enginee Weekly No.3, W.III.

[6] Putri, A. D., Sugiono, \& Sari, A. R. (2014). "Pemilihan Alternatif Peluang Hemat Energi Listik Dengan Pendekatan Metode ANP dan P". Jurnal Rekayasa Dan Manajemen Sistem Industri Vol.3 No.1, 142-153.

[7] Sari, Hayuning, \& Putranto, Ary.(2018). "Konsep Bangunan Hijau Pada Gedung Fakultas Ilmu Administrasi Universitas Brawijaya. http://arsitektur.studentjournal.ub.ac.id.

[8] Sobirin, Zainal, A., \& Cahyaka, Hendra,W. (2014). "Analisis Kesesuaian Desain Gedung Olahraga Baru Universitas Negeri Surabaya Terhadap Konsep Green Building”. Jurnal Rekayasa Teknik Sipil Vol 3. No.1, 29-36.

[9] Triana, V. (2008). "Pemanasan Global". Jurnal Kesehatan Masyarakat, Maret 2008-September 2008, II (2). 